\section{ESPORTE, FUNDO PÚBLICO E PEQUENA POLÍTICA: OS REVESES DE UM ORÇAMENTO (R)EMENDADO}

\author{
SPORTS, PUBLIC FUND AND NARROW SMALL POLITICS: THE DOWNSIDES \\ OF AN AMENDED BUDGET
}

\begin{abstract}
DEPORTE, FINANCIACIÓN PÚBLICA Y PEQUEÑA POLITICA: LOS REVESES DE UN PRESUPUESTO CON ENMIENDAS
\end{abstract}

\section{Marcelo Resende Teixeira*, Fernando Henrique Carneiro**, Fernando Mascarenhas***, Wagner Barbosa Matias*}

Palavras chave:

Estado.

Esportes.

parlamentares
Emendas

Resumo: 0 estudo aborda a relação entre Estado e políticas esportivaspor meio de uma análise orçamentária das emendas parlamentares vinculadas ao Ministério do Esporte. O objetivo foi verificar a efetivação das emendas deste órgão, seu direcionamento (contemplados) e valoresrelativos ao período de 2008 a 2015. A abordagem foi de caráter quantitativo-qualitativo, sendo realizada uma pesquisa bibliográfica e um levantamento documental. Para a análise dos dados foi adotado o método proposto por Boschetti (2009), em seu aspecto: "configuração do financiamento e gasto". Concluiu-se que as emendas representaram naquele período cerca de $52 \%$ da composição orçamentária do órgão, sendo utilizadas majoritariamente para atender interesses dos parlamentares em suas bases eleitorais em obras de infraestrutura esportiva.

Keywords:

State.

Sports.

Parliamentary amendments.

Palabras clave: Estado.

Deportes.

Enmiendas parlamentarias
Abstract: The study approaches the relationship between the State and sports policies through a budget-based analysis of parliamentary amendments linked to the Ministry of Sports. The objective was to verify the effectiveness of the amendments to the agency's budget, their (accepted) aims, and the values for 2008-2015. The study was quantitativequalitative, including a bibliographical review and a documentary survey. The analysis of the data adopted the method proposed by Boschetti (2009) in its aspect related to "configuration of funding and expense". It found out that the amendments represented about $52 \%$ of the Ministry's budget for that period and were used mainly to serve the interests of Congress members regarding sports infrastructure works in their constituencies.

Resumen: El estudio aborda la relación entre Estado y políticas deportivas por medio de un análisis presupuestario de las enmiendas parlamentarias vinculadas al Ministerio del Deporte. El objetivo fue verificar la efectivación de las enmiendas de ese organismo, su direccionamiento (contemplados) y valores relativos al período de 2008 a 2015 . El abordaje tuvo carácter cuantitativo-cualitativo, realizando una búsqueda bibliográfica y un levantamiento documental. Para el análisis de los datos se adoptó el método propuesto por Boschetti (2009), en su aspecto: "configuración de la financiación y gasto". Se concluyó que las enmiendas representaron en aquel período cerca del $52 \%$ de la composición presupuestaria de ese organismo, y que en su mayoría se utilizaron para atender a intereses de los parlamentarios en sus bases electorales en obras de infraestructura deportiva..
*Ministério do Esporte. Brasília, DF, Brasil.

E-mail: marinresende@yahoo.com.br; wagner.matias@outlook.com

**Instituto Federal Goiano e Universidade de Brasília. Brasília,DF, Brasil.

E-mail: fernandohenriquesc@gmail.com

***Universidade de Brasília. Brasília, DF, Brasil.

E-mail: fernando.masca@outlook.com

Recebido em: 29-04-2017 Aprovado em: 02-05-2018

DOI: http://dx.doi.org/10.22456/1982-8918.73007 (c) (1) (8) Licence 


\section{INTRODUÇÃO}

O esporte se constituiu legalmente como um direito no Brasil a partir da Constituição Federal de 1988. Ao consignar em seu art. 217 como dever do Estado o fomento às práticas esportivas, o texto constitucional passou a prever a realização de investimentos públicos na promoção do esporte ${ }^{1}$.Nesse sentido, nos últimos anos diversificaram-se as fontes e ampliouse o montante, ainda que de forma não linear, dos recursos alocados pelo Governo Federal para o financiamento desse fenômeno(ATHAYDE; SALVADOR; MASCARENHAS, 2015; MASCARENHAS, 2016; MATIAS et al. 2015).

Vale destacar que as políticas públicas esportivas são concretizadas tendo por base 0 fundo público. Este desempenha um importante papel na estabilização macroeconômica, na alocação de recursos para a provisão de bens e serviços, assim como na distribuição de renda entre os diversos segmentos da sociedade. A face mais visível dele, seja no âmbito geral ou no âmbito esportivo, é o orçamento federal (SALVADOR, 2008).

A produção acadêmica aplicada ao financiamento das políticas esportivas no cenário brasileiro vem se consolidando em estudos como de Veronez (2005); Boudens (2007); Almeida (2010); Castelan (2011); Matias et al. (2015); Athayde, Salvador e Mascarenhas (2015);Teixeira, Matias e Mascarenhas (2015); Mascarenhas (2016); Castro (2016); Teixeira (2016); Guimarães (2017); entre outros.

Em alguns desses trabalhos, a saber: Veronez (2005), Boudens (2007), Castelan (2011), Castro (2016), Mascarenhas (2016), Teixeira (2016) e Guimarães (2017), menciona-se a atuação do Poder Legislativo influenciando a aplicação dos recursos destinados ao esporte, notadamente por meio de emendas parlamentares ${ }^{2}$, as quais invariavelmente culminam com projetos clientelistas responsáveis por uma pulverização dos recursos públicos, ou seja, pela distribuição por inúmeras obras, geralmente com recursos insuficientes para a conclusão dos projetos e ainda por sua destinação "carimbada". 0 empenho dos parlamentares na "corrida" pelos recursos do fundo público ocorre pela possibilidade de eles atenderem os compromissos políticos assumidos antes e no decorrer de seus mandatos, tanto junto aos estados e municípios, quanto às instituições (BEZERRA, 1999).

Nos termos de Gramsci (2003), tal cenário é propício ao predomínio crescente de uma prática que limita o horizonte estratégico da política, convertendo-a em mera técnica para a obtenção de eventuais maiorias parlamentares. Para o autor citado acima, enquanto a grande política assume como horizonte a fundação de um novo Estado e a luta pela defesa e conservação de uma determinada estrutura social e política, expressando uma nova visão de mundo, a pequena política reduz os conflitos às escaramuças parlamentares e às lutas pelo predomínio no interior de uma estrutura já estabelecida.

Importante mencionar que as expressões da pequena política se vinculam à própria formação do Estado brasileiro, marcada pela utilização estatal como instrumento de apropriação de poder e riqueza pelos setores e grupos dirigentes, quer dizer, os interesses

1 Para Mascarenhas (2016),a participação do Estado no financiamento esportivo já aparece desde o Decreto-lei no 3.199/1941, que previa a subvenção federal para entidades esportivas e outras medidas de proteção - isenção de impostos e taxas - para realização de eventos, importação de equipamentos e participação de atletas em competições internacionais.

2 As emendas de parlamentares ao orçamento federal influem na alocação de recursos públicos. Tais emendas podem acrescentar, suprimir ou modificar determinados itens (rubricas) do projeto de lei orçamentária enviado pelo Executivo todos os anos. 
públicos e coletivos são submetidos aos interesses privados e particulares. Nessa dinâmica, 0 clientelismo representa a consolidação desse processo, baseado na troca de favores dentro de uma relação política por apoio, tendo, por exemplo, no voto, uma possível moeda de troca por benesses entre aqueles que detêm o controle do Estado e aqueles que votam (COUTINHO, 2010).

Como consequência, os deputados e senadores são um dos elos superiores de uma rede de clientela, que passa por níveis intermediários até chegar ao cabo eleitoral e seus eleitores (clientes). Esse processo de desarticulação do Legislativo tem sido prejudicial, gerando um enfraquecimento do Congresso na sua relação com o Executivo, ficando em segundo plano a grande política.

Em 2003, com a chegada ao poder da coalizão liderada pelo Partido dos Trabalhadores (PT), tinha-se a expectativa da priorização de políticas que garantissem os direitos sociais, bem como a materialização do rompimento da lógica da pequena política (MATIAS, 2013). Entretanto, ao social coube a efetivação de políticas focalizadas e principalmente de combate à pobreza, expressas pelo direcionamento do fundo público, e a permanência da cultura de atuação da "política de corredor", sem transformações estruturais (COUTINHO, 2010; GONÇALVES, 2013).

No caso esportivo, as ações do Ministério do Esporte (ME) inicialmente sinalizaram para possibilidade de ruptura com a dinâmica até então existente, uma vez que foram criados programas com princípios inovadores que se pautavam pela democratização da prática esportiva. Além disso, se instituíram espaços de debate das políticas desenvolvidas (Conferências Nacionais do Esporte - CNE), culminando com a sinalização da implementação de um Sistema Nacional do Esporte (MATIAS, 2013). Todavia, a prioridade da agenda esportiva não foi a ampliação do acesso ao esporte e sim os investimentos em infraestrutura esportiva e a realização de megaeventos esportivos, sendo de forma secundária o gasto com programas sociais de esporte e lazer (MASCARENHAS, 2016).

Tal opção, além de injetar um montante considerável de recursos no setor, também confirmou a relação entre esses megaeventos com a política "neodesenvolvimentista" implementada nos governos Lula e Dilma, a qual se caracterizou em estímulos de gastos públicos para minimizar os efeitos da crise no país. Dessa forma, nota-se claramente que, no decorrer dos anos, os investimentos no esporte contemplaram, nos termos de Mandel (1985), prioritariamente a função diretamente econômica (criação das condições gerais de produção) por meio dos gastos com infraestrutura e megaeventos.

Conforme Veronez (2005), Boudens (2007), Castelan (2011), Castro (2016), Teixeira (2016) e Guimarães (2017), observa-se que parte dos recursos utilizados pelo ME é oriunda de emendas parlamentares. Anualmente os deputados e senadores vinculam no orçamento da União um montante que deve ser destinado para os Ministérios desenvolverem as suas ações conforme a indicação dos congressistas. Desses estudos mais recentes notam-se avanços sobre o entendimento da composição orçamentária do ME, da representatividade das emendas, notadamente em ações de infraestrutura, das transformações orçamentárias em prol dos megaeventos e consequentemente o impacto desses achados no desenvolvimento das políticas esportivas da pasta (CASTELAN, 2011; CASTRO, 2016; GUIMARÃES, 2017; TEIXEIRA, 2016). 
Desse modo, surge a seguinte questão como ponto de partida desta investigação: qual o lugar e o significado das emendas parlamentares no orçamento do ME? Para responder tal questionamento, parte-se do suposto de que as emendas parlamentares vinculadas ao orçamento esportivo não se efetivam de uma maneira orgânica ao planejamento do setor, assim como se revelam instrumento de atuação dos deputados e senadores no intuito de atender às suas bases eleitorais. Portanto, este texto tem como objetivo verificar o papel das emendas parlamentares na constituição do orçamento do ME, seu direcionamento e gasto no período de 2008 a 2015.

\section{DELINEAMENTO METODOLÓGICO}

A unidade de análise é o $\mathrm{ME}$, no que tange aos seus recursos orçamentários ${ }^{4}$. A abordagem adotada foi de caráter quantitativo-qualitativo, apoiando-se em levantamento documental junto ao SIGA Brasil $\left(\mathrm{SB}^{5}\right)$. Ao mesmo tempo, no sentido de organização dos dados, optou-se pelos Planos Plurianuais (PPAs), a saber: período 1 - PPA 2008/2011 e período 2 - PPA 2012/2015 em suas respectivas execuções orçamentárias. A pesquisa bibliográfica subsidiou a análise sobre os dados encontrados, tendo em vista que possibilitou o entendimento das relações entre o Estado brasileiro e suas imbricações nas políticas esportivas. A partir desta opção, foi possível analisar as emendas por:

a) comparativo dos recursos do orçamento do ME com das emendas vinculadas ao órgão6;

b) tipologia;

c) ação/objeto;

d) coligação partidária.

É importante sinalizar que o SB possibilitava até 2016, em aba específica, o valor global das emendas vinculadas aos órgãos, portanto, mesmo que sejam sancionadas, os valores passam a estar sob uma mesma funcional. Ao realizar a subtração dos recursos vinculados ao orçamento do ME (função desporto e lazer), o qual também é obtido em aba apropriada, chega-se aos valores específicos das emendas.

A análise perpassa o período dos dois últimos PPAs elaborados pelos governos de coalizão liderados pelo PT (2008 a 2015), entretanto, somente a partir de 2009 os dados de execução de emendas por órgão foram possibilitados pelo SB. Os dados de 2008 também foram coletados na ferramenta SB, contudo, não por órgão e sim por autor. Assim, ao considerar o valor somado pelos autores com emendas esportivas, também subtraímos do orçamento da função desporto e lazer.

Foi adotado o método de análise de políticas sociais proposto por Boschetti (2009), em seu aspecto "configuração do financiamento e gasto", no que tange aos indicadores direção e magnitude do gasto. A direção do gasto se refere à alocação de recursos de uma política, já a magnitude permite analisar o volume de recursos, no sentido de verificar se houve manutenção, crescimento, redução ou realocação ${ }^{7}$.

$4 \mathrm{~A}$ base de financiamento do esporte é diversa, contando com variadas fontes de recursos: fontes orçamentárias, extraorçamentárias e indiretas (MASCARENHAS, 2016).

5 O SIGA Brasil é um sistema de informações sobre orçamento público federal, que permite acesso amplo e facilitado aos dados do Sistema Integrado de Administração Financeira (SIAFI) e a outras bases de dados sobre planos e orçamentos públicos. 
Destaca-se a seguir o lugar das emendas parlamentares efetivadas ao ME, mapeando e caracterizando sua magnitude e direcionamento, bem como problematizando as relações existentes entre os poderes Executivo/Legislativo nas ações contempladas via emendas dentro das políticas esportivas desenvolvidas pelo ME.

\section{AS EMENDAS PARLAMENTARES NO ORÇAMENTO DO ESPORTE}

É importante mencionar que os PPAs são executados a partir do segundo ano de governo, estendendo-se até o primeiro ano do governo seguinte, portanto, os dados de 2011, apesar de serem do PPA elaborado no governo Lula, foram executados no governo Dilma. Isto posto, no que tange aos recursos orçamentários do ME que são provenientes de emendas no período de 2008 a 2015, observa-se grande participação e oscilação delas, principalmente nos anos relativos ao PPA 2008/2011, com dois picos expressivos em 2008 e 2009.

O cenário pode ser explicado pelo fato de o governo Lula ter tido um melhor relacionamento com os congressistas devido à coalizão realizada, além das emendas. Conforme Bezerra (1999), representa um dos principiais instrumentos de articulação política entre o Planalto e o Congresso, fato ilustrado pelos números do orçamento geral, pois nos anos de governo do ex-presidente Luiz Inácio Lula da Silva as emendas aumentaram em $550 \%$, só entre 2008 a 2009 saltaram de $R \$ 6$ milhões para $R \$ 10$ milhões $^{8}$. A Tabela 1 apresenta os principais resultados dentro do orçamento do ME.

Tabela 01 - Comparativo entre Orçamento ME x Emendas Parlamentares ME - Série 2008-2015 (valores liquidados; valores deflacionados pelo IGP-DI em $\mathrm{R} \$$ bilhões e \%)

\begin{tabular}{cccc}
\hline \multicolumn{5}{c}{ Período 1: PPA 2008/2011 } \\
\hline Ano & Orçamento ME & Valor emendas liquidadas ME & $\%$ \\
\hline 2008 & 1,4 & 1,2 & $86 \%$ \\
2009 & 1,4 & 1,2 & $86 \%$ \\
2010 & 1,4 & 0,7 & $50 \%$ \\
2011 & 1,5 & 01 & $66 \%$ \\
\hline Total Período 1 & $\mathbf{5 , 7}$ & $\mathbf{4 , 1}$ & $\mathbf{7 2 \%}$ \\
\hline $\mathbf{2 0 1 2}$ & Período 2: PPA 2012/2015 & \\
2013 & 0,5 & 0,04 & $8 \%$ \\
$\mathbf{2 0 1 4}$ & 0,4 & 0,07 & $17,5 \%$ \\
$\mathbf{2 0 1 5}$ & 0,9 & 0,09 & $10 \%$ \\
\hline Total Período 2 & 0,6 & 0,10 & $16 \%$ \\
\hline Junção dos Períodos 1 e 2 & $\mathbf{2 , 4}$ & $\mathbf{0 , 3}$ & $\mathbf{1 2 , 5 \%}$ \\
\hline & $\mathbf{8 , 5}$ & $\mathbf{4 , 4}$ & $\mathbf{5 2 \%}$ \\
\hline
\end{tabular}

No panorama geral, de 2008 a 2011 os valores das emendas flutuaram entre $86 \%$ e $50 \%$ do total dos recursos liquidados do ME, sendo que a média do período foi de $72 \%$ do orçamento ministerial. Por outro lado, no PPA 2012/2015, nota-se uma constante, sendo que 
as emendas variaram apenas entre $8 \%$ e $17,5 \%$ do orçamento do ME. Não obstante, há uma decrescente dos percentuais relacionados às emendas, quando a avaliação é realizada aos valores auferidos durante os últimos anos de governo Lula e parte do primeiro mandato do governo Dilma.

De maneira geral, as emendas parlamentares cumpriram um papel importante no orçamento do $\mathrm{ME}$, haja vista ter sido mais da metade $(52 \%)$, ratificando o caráter autorizativo do orçamento, pois as emendas são utilizadas pelo Poder Executivo como um instrumento de barganha política, ou seja, seus desembolsos são efetivados em retribuição a voto ou posicionamento favorável do parlamentar em assuntos do interesse do Palácio do Planalto, reforçando práticas tradicionais (clientelistas) na política brasileira9 (TEIXEIRA, 2016).

Contudo, embora os números traduzam um significativo incremento de recursos no orçamento via emendas, de maneira especial no período 1, também se nota que grande parte do estabelecido em lei orçamentária não se efetiva como gasto (liquidado). Podemos identificar pelas fases da execução orçamentária (Tabela 2) a discrepância entre o que foi aprovado como emenda, o previsto na Lei Orçamentária Anual - LOA (dotação inicial) - a qual se eleva devido à indicação sem previsão de receita pelos parlamentares (2009, 2011, 2012, 2013, 2014 e 2015) - e o autorizado, o empenhado e o liquidado. Assim, depois de aprovado e sancionado 0 orçamento, o Ministério do Planejamento é obrigado a realizar tais ajustes, isto é, reter verbas, ajustar os gastos à arrecadação, contingenciar (BOUDENS, 2007) ${ }^{10}$.

Tabela 02 - Execução orçamentária das emendas parlamentares do ME - Série 2008-2015 (valores liquidados; valores deflacionados pelo IGP-DI em R\$ bilhões)

\begin{tabular}{cccccc}
\hline Ano & $\begin{array}{c}\text { Valor emendas } \\
\text { aprovadas ME }\end{array}$ & Dotação inicial & Autorizado & Empenhado & Liquidado \\
\hline $\mathbf{2 0 0 8}$ & 1,4 & 1,4 & 1,7 & 1,2 & 1,2 \\
$\mathbf{2 0 0 9}$ & 1,5 & 1,9 & 1,8 & 1,2 & 1,2 \\
$\mathbf{2 0 1 0}$ & 1,5 & 1,5 & 1,5 & 0,7 & 0,7 \\
$\mathbf{2 0 1 1}$ & 1,6 & 2,1 & 2,1 & 1,0 & 1,0 \\
$\mathbf{2 0 1 2}$ & 1,2 & 1,5 & 1,5 & 0,6 & 0,04 \\
$\mathbf{2 0 1 3}$ & 1,7 & 2,3 & 2,2 & 1,3 & 0,07 \\
$\mathbf{2 0 1 4}$ & 0,7 & 1,1 & 1,2 & 0,7 & 0,09 \\
$\mathbf{2 0 1 5}$ & 0,7 & 4,5 & 4,5 & 2,3 & 0,10 \\
\hline TOTAL & 10,3 & $\mathbf{1 6 , 6}$ & $\mathbf{1 6 , 8}$ & $\mathbf{9 , 4}$ & 4,4 \\
\hline \multicolumn{5}{c}{ Fonte: SIGA Brasil. (elaboração dos autores) } \\
\hline
\end{tabular}

A Tabela 2 ainda possibilita a análise do movimento orçamentário por meio dos créditos adicionais, que são um mecanismo de ajuste para autorizar despesas não mencionadas ou insuficientemente dotadas na LOA. Tais créditos têm por objetivo atender a alterações de rumo das políticas públicas, as variações de preço de mercado dos bens e serviços a serem adquiridos pelo governo ou, ainda, a situações emergenciais, fato identificado nos anos de 2008 e 2014 que culminam com alteração entre as fases de dotação inicial e 0 autorizado.

9 O Congresso Nacional, em 17/03/2015 aprovou a Emenda Constitucional 86,a qual estabeleceu um valor mínimo de emendas parlamentares que devem, obrigatoriamente, ser executadas no ano seguinte. Esse valor equivale a 1,2\% da receita corrente líquida do ano anterior. 
Ao mesmo tempo, considerando que as emendas, em especial as individuais, estão usualmente incluídas dentro dos $10 \%$ da despesa orçamentária sujeita a contingenciamento ${ }^{11}$, reiteramos o potencial de barganha política à disposição do Poder Executivo. Deste modo, sempre que foi necessário ajustar o reforço de sua base de apoio no Congresso, o Executivo descontingenciou parte das emendas em retribuição a voto ou posicionamento favorável do parlamentar. Situação melhor administrada pelo governo Lula em relação ao governo Dilma, visto que o orçamento é emendado e aprovado em um ano, mas sua liquidação e execução podem ocorrer nos anos subsequentes.

Por essa razão, os desembolsos realizados para convênios, contratos ou instrumentos congêneres demonstram que também no esporte há limites para a efetivação dos gastos das emendas, representando cerca de $43 \%$ entre o aprovado e o liquidado em todo o período. Ao isolarmos os dados dentro de seus respectivos PPAs (2008/2011 e 2012/2015), podemos verificar dois movimentos, sendo o primeiro a liquidação até considerável dos valores aprovados (68\%), e o segundo o decréscimo total, culminando com o percentual de apenas $7 \%$ - isto seria parte da explicação sobre o porquê a presidenta Dilma teve dificuldades em sua relação com o Poder Legislativo, materializada pelo seu impedimento.

Pelo exposto, tais considerações vêm de encontro à afirmação proferida por Boschetti (2003), ou seja, emenda aprovada não é sinônimo de emenda liquidada e consequentemente paga. Por serem facultativas ao Executivo, as emendas são moedas de troca, uma espécie de cheque pré-datado para a cooptação do Parlamento pelo Executivo, ou seja, a mais pura configuração da efetivação de práticas clientelistas e da pequena política (BEZERRA, 1999; COUTINHO, 2010; PEREIRA; MULLER, 2002).

A oscilação entre os períodos 1 e 2 pode ser ainda entendida, tendo em vista que no primeiro ano do período, a saber,2012, o ME teve uma baixa execução orçamentária, assim como o fato de que até o primeiro quadriênio do mesmo ano o órgão ministerial possuía uma força-tarefa para análise de todos os convênios com Organizações Não Governamentais (ONGs), conforme o Decreto Presidencial n-7.592/2011, motivado pelas denúncias de desvio e uso inadequado de recursos por ONGs. Além disso, ressaltam-se ainda as seguidas trocas dos gestores da pasta esportiva, pois desde o fim de 2011, o ME sofreu várias alterações em seu comando. Assim, esse conjunto de fatores pode ter influenciado a divergência entre os empenhos e limitado as liquidações das despesas do período vinculado ao PPA 2012/2015 (TEIXEIRA; MATIAS; MASCARENHAS, 2015).

\subsection{Tipologia das emendas}

Para Boschetti (2003), as emendas são classificadas em individuais e do relator ou coletivas. Estas se dividem em emendas de comissão e de bancada estadual. Registre-se que as emendas individuais são apresentadas com destino, objeto e montantes especificados. As emendas do relator são feitas pelo deputado ou senador que, naquele determinado ano, foi escolhido para produzir o parecer final sobre o Orçamento. As de bancada são emendas coletivas de autoria das bancadas estaduais ou regionais. Já as emendas de comissão são aquelas propostas pelas mesas diretoras da Câmara dos Deputados e Senado Federal (CASTRO, 2016).

11 Normalmente, no início de cada ano, o Governo Federal emite um Decreto limitando os valores autorizados na LOA, relativos às despesas discricionárias ou não legalmente obrigatórias (investimentos e custeio em geral). 
Do total de recursos liquidados no período de análise (2008 a 2015), conforme a Tabela 3 , percebe-se diferenças entre os períodos, tendo em vista a preeminência das emendas individuais no período 1, culminando com sua maior representação em toda a série, tanto em termos quantitativos, como em valores monetários.

Tabela 03 - Distribuição por tipos de emendas do ME - Série 2008-2015 (valores liquidados; valores deflacionados pelo IGP-DI em R\$ bilhões e \%).

\begin{tabular}{ccccc}
\hline Tipo de emendas & $\mathbf{n}$ - emendas & $\%$ & $\mathbf{R} \$$ & $\%$ \\
\hline \multicolumn{5}{c}{ Período 1: PPA 2008/2011 } \\
\hline Individual & 2392 & $98,39 \%$ & 3,9 & $93,07 \%$ \\
Comissão & 09 & $0,37 \%$ & 0,19 & $4,53 \%$ \\
Relator & 04 & $0,16 \%$ & 0,07 & $1,67 \%$ \\
Bancada & 27 & $1,06 \%$ & 0,03 & $0,71 \%$ \\
\hline \multicolumn{5}{c}{ Período 2: PPA 2012/2015 } \\
\hline Comissão & 09 & $3,87 \%$ & 0,15 & $40,54 \%$ \\
Relator & 06 & $2,58 \%$ & 0,09 & $24,32 \%$ \\
Individual & 216 & $93,10 \%$ & 0,07 & $18,91 \%$ \\
Bancada & 01 & $0,43 \%$ & 0,06 & $16,21 \%$ \\
\hline
\end{tabular}

Fonte: Siga Brasil. Elaboração dos autores (2017).

Para Boschetti (2003), o predomínio de recursos pagos pelas emendas de comissão pode ser visto como positivo, sendo que estas são nacionais, ou seja, são carimbadas quanto às ações, valores e natureza de despesa, mas não estão marcadas quanto ao destino, sua aplicação é definida geralmente pelo próprio ministério; houve o predomínio desta no período 2. Já quando o predomínio se efetiva pelas emendas individuais a autora sinaliza como prejudicial, a julgar que estas são apresentadas com destino, objeto e montante especificados, atendendo assim a interesses particularistas dos legisladores; ocorreu dominância absoluta destas no período $1^{12}$.

Vale ainda esclarecer que as emendas coletivas dos parlamentares têm sido utilizadas, na prática, como se fossem individuais, em que pese às regras do procedimento permitir que todos os correligionários da mesma bancada assinem as emendas, sem critérios definidos quanto às prioridades em questão. Observa-se também que as emendas das comissões também podem ser utilizadas como individuais, já que as lideranças partidárias realizam acordos nesse sentido, notadamente com o ministro da pasta a qual será rubricada a emenda, ampliando, assim, a possibilidade de ganhos individuais por meio de tais instrumentos (BEZERRA, 1999; BOSCHETTI, 2003).

\subsection{Direcionamento das emendas}

Utilizando as categorias desenvolvidas por Mascarenhas (2016) para analisar 0 orçamento do esporte - Esporte Educacional, Lazer e Inclusão Social-EELIS, Esporte de Alto Rendimento-EAR, Gestão, Megaeventos e Infraestrutura -, é possível verificar o direcionamento das emendas dentro das ações/objeto do ME. A Tabela 4 consigna as informações coletadas.

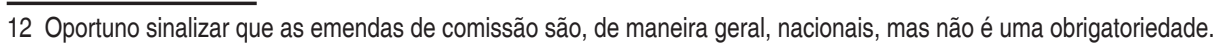


Tabela 04 - Direcionamento por categorias das emendas do ME - Série 2008-2015 (valores liquidados; valores deflacionados pelo IGP-DI em R\$ bilhões e \%).

\begin{tabular}{|c|c|c|c|c|c|c|c|c|c|c|c|c|}
\hline \multicolumn{13}{|c|}{ Período 1 (PPA 2008/2011) } \\
\hline \multirow{2}{*}{$\begin{array}{c}\text { Ano } \\
\text { Categoria }\end{array}$} & \multicolumn{2}{|c|}{2008} & \multicolumn{2}{|c|}{2009} & \multicolumn{2}{|c|}{2010} & \multicolumn{2}{|c|}{2011} & \multicolumn{4}{|c|}{ TOTAL } \\
\hline & № & $\mathbf{R} \$$ & № & $\mathbf{R} \$$ & № & $\mathbf{R} \$$ & № & $\mathbf{R} \$$ & № & $\%$ & $\mathbf{R} \$$ & $\%$ \\
\hline Infraestrutura & 726 & 1,1 & 672 & 1,2 & 495 & 0,7 & 356 & 0,9 & 2249 & 92,4 & 3,9 & 94,20 \\
\hline EELIS & 43 & 0,08 & 43 & 0,04 & 59 & 0,01 & 21 & 0,08 & 166 & 6,8 & 0,2 & 4,83 \\
\hline EAR & 03 & 0,01 & 02 & 0,001 & 05 & 0,01 & 05 & 0,008 & 15 & 0,61 & 0,02 & 0,48 \\
\hline Gestão & 01 & 0,01 & 00 & 00 & 00 & 00 & 00 & 00 & 01 & 0,04 & 0,01 & 0,24 \\
\hline \multirow[t]{2}{*}{ Megaeventos } & 00 & 00 & 00 & 00 & 00 & 00 & 01 & 0,01 & 01 & 0,04 & 0,01 & 0,24 \\
\hline & & & & & & & \multicolumn{2}{|r|}{ TOTAL } & 2432 & 100 & 4,1 & 100 \\
\hline \multicolumn{13}{|c|}{ Período 2 (PPA 2012/2015) } \\
\hline Ano & \multicolumn{2}{|c|}{2012} & \multicolumn{2}{|c|}{2013} & \multicolumn{2}{|c|}{2014} & \multicolumn{2}{|c|}{2015} & \multicolumn{4}{|c|}{ TOTAL } \\
\hline Categoria & № & $\mathrm{R} \$$ & № & $\mathbf{R} \$$ & № & $\mathrm{R} \$$ & № & $\mathrm{R} \$$ & № & $\%$ & $\mathrm{RS}$ & $\%$ \\
\hline EELIS & 01 & 0,01 & 01 & 0,02 & 13 & 0,08 & 01 & 0,07 & 16 & 07 & 0,18 & 60 \\
\hline EAR & 00 & 00 & 01 & 0,03 & 01 & 0,01 & 01 & 0,03 & 03 & 01 & 0,07 & 24 \\
\hline Infraestrutura & 203 & 0,01 & 02 & 0,01 & 02 & 0,006 & 01 & 0,007 & 208 & 90 & 0,02 & 09 \\
\hline Gestão & 01 & 0,02 & 00 & 00 & 04 & 0,001 & 00 & 00 & 05 & 02 & 0,02 & 07 \\
\hline \multirow[t]{2}{*}{ Megaeventos } & 00 & 00 & 00 & 00 & 00 & 00 & 00 & 00 & 00 & 00 & 00 & 00 \\
\hline & & & & & & & & TOTAL & 232 & 100 & 0,3 & 100 \\
\hline
\end{tabular}

Fonte: Siga Brasil. Elaboração dos autores (2017).

Pode ser observado no período 1 que houve o predomínio significativo de recursos para Infraestrutura, tanto em quantitativo, quanto em recursos, uma vez que seus percentuais foram de $94,2 \%$ desta e $92,4 \%$ daquela. Ao verificarmos a ação/objeto contemplada nessa categoria, nota-se seu direcionamento à implantação e modernização de infraestrutura para esporte recreativo e de lazer, vinculadas quase totalmente ao Programa Esporte e Lazer da Cidade (PELC $\left.{ }^{13}\right)$.

As demais categorias pela ordem pecuniária apresentam números tímidos no período 1, a saber: EELIS (4,83\%); EAR (0,48\%); Gestão (0,24\%) e Megaeventos (0,24\%). Ao consideramos o ranking das categorias privilegiadas pelas emendas, nota-se que este se assemelha aos dados encontrados nos estudos desenvolvidos por Mascarenhas (2016) e Carneiro ${ }^{14}$ sobre 0 orçamento geral do esporte, ficando apenas a categoria Megaeventos fora de sintonia, pois no período 1 representou cerca de $23 \%$, perdendo apenas para Infraestrutura, com $52 \%$.

Considerando os dados do período 2 , sinaliza-se uma ruptura com a sistemática até então desenvolvida pelo ME, pois, ainda que em termos quantitativos a categoria Infraestrutura represente $90 \%$ do total, na questão monetária a maior beneficiada foi EELIS, com 60\% dos recursos, seguida por EAR (24\%), a própria Infraestrutura (9\%) e Gestão (7\%). Percebe-se que a categoria Megaeventos sequer foi contemplada nesse período, com recursos via emendas.

Para explicar a desproporção entre os períodos 1 e 2, recorremos a Carneiro ${ }^{14}$ sobre sua análise do orçamento do esporte em que apontou que ao redirecionar a agenda e

13 Sabe-se que tal ação foi vinculada sob gerência da Secretaria Executiva do ME e não do PELC, que em suas diretrizes proporciona a prática de atividades físicas, culturais e de lazer envolvendo todas as faixas etárias e as pessoas portadoras de deficiência, estimulando a convivência social, a formação de gestores e lideranças comunitárias, favorecendo a pesquisa e a socialização do conhecimento. 
financiamento esportivo em favor dos Megaeventos, a categoria protagonista das emendas no período 1 (Infraestrutura) teve diminuição drástica de recursos. Tanto que no orçamento do esporte, Infraestrutura ${ }^{15}$ saiu de 52\% no PPA 2008/2011 para apenas 25\% no PPA 2012/2015, enquanto Megaeventos saltou de $23 \%$ para $35 \%$, respectivamente.

A queda dos recursos para Infraestrutura se relaciona à própria opção do governo Dilma de privilegiar emendas de relator e de comissão, essas como vimos anteriormente possuem um apelo menor entre os parlamentares devido às suas características diferentes das individuais, tendo em vista que seu direcionamento não é compulsório, isto é, são encaminhadas/implementadas pelos ministérios e não diretamente pelos congressistas.

Não obstante, considerando o total de 2008a2015, a categoria Infraestruturaé protagonista tanto em relação ao orçamento geral do esporte (representou $36 \%$ dos recursos), quanto no que diz respeito às emendas, influenciada de maneira especial pelo período 1 , significa $88 \%$ dos recursos. Assim, mesmo ponderando a oscilação entre os períodos 1 e 2, influenciada pelo dinâmica orçamentária do ME em favor dos Megaeventos, entendemos que o ME tem assumido uma postura denominada por Mascarenhas (2016), de "ministério de obras". Tal fato não deveria se configurar, uma vez que falta ao órgão estrutura e pessoal para o acompanhamento e fiscalização dos projetos aprovados, o que tende a favorecer o desenvolvimento de irregularidades e ilícitos (CARNEIRO'16; MASCARENHAS, 2016; TEIXEIRA, 2016).

Esses dados vêm ao encontro do estudo desenvolvido por Boschetti (2003), por meio do qual constatou que os parlamentares preferem investir mais em ações de construção, ampliação e/ou aquisição de equipamentos, os quais ela designou de emendas de capital, do que na manutenção de atividades e ações já existentes, as chamadas emendas de custeio. Portanto, o foco é vincular razão objetiva e "concreta", no termo literal da palavra, para fins eleitorais, na medida em que os cidadãos veem a materialização do que foi "feito" pelo parlamento.

\subsection{Distribuição das emendas por coligação partidária e apoios}

Considerando os dados do Tribunal Superior Eleitoral (TSE) sobre as coligações, bem como os apoios formalizados para as eleições presidenciais nos anos de 2006 e 2010, podem ser criadas categorias de vínculo, a saber: a) partidos da base governista - coligações e partidos que demonstraram apoio, em primeiro ou segundo turno, à candidatura de Lula em 2006 e Dilma em 2010; b) partidos opositores; c) aqueles declarados independentes e d) outros.

Houve aumento da base governista entre as duas eleições, saltando de cinco partidos em 2006 para dez em 2010. Fato correlacionado com o sucesso da coalizão presidencialista, assim como pelo alto índice de avaliação do governo Lula, chegando a $77 \%$ da população a avaliar a gestão do petista como ótima ou boa, às vésperas das eleições de $2010^{17}$.

$\mathrm{Na}$ análise dos dados, considerando os recursos apenas das emendas individuais direcionadas ao ME, revela-se o predomínio da base aliada do governo em toda série histórica, conforme a seguir na Tabela 5:

15 Registre-se que além da possibilidade do direcionamento das emendas parlamentares para a categoria Infraestrutura existem ações e programas específicos no Ministério do Esporte, a saber: Rede Nacional de Treinamento, Centro de Iniciação ao Esporte, Praças da Juventude e Praças do PAC.

16 CARNEIRO, Fernando Henrique. O orçamento do esporte no PPA - 2012/2015. (No prelo). 
Tabela 05 - Distribuição por coligação partidária e apoios das emendas do ME - Série 2008-2015 (valores liquidados; valores deflacionados pelo IGP-DI em R\$ bilhões e \%).

\begin{tabular}{ccccc}
\hline Períodos & \multicolumn{2}{c}{ Período 1: PPA 2008/2011 } & \multicolumn{2}{c}{ Período 2: PPA 2012/2015 } \\
\hline Posicionamento & R\$ & $\%$ & R\$ & $\%$ \\
\hline Base governista & 1,7 & 43,5 & 0,056 & 80 \\
Oposição & 1,2 & 30,8 & 0,012 & 17 \\
Independente & 1 & 25,7 & 0,001 & 1,5 \\
Outros & 0 & 0 & 0,001 & 1,5 \\
\hline
\end{tabular}

Fonte: Tribunal Superior Eleitoral e Siga Brasil. Elaboração dos autores (2017).

Com o aumento da coligação partidária pró-governo nas eleições de 2010, a prerrogativa em atendimento da base aliada se fortalece, uma vez que, no período 2, nem mesmo o tamanho das bancadas foi suficiente para modificar os números encontrados. Até porque, como temos sinalizado ao longo do texto, a partir do PPA 2012/2015 houve um menor atendimento das emendas como um todo, de maneira especial as individuais.

Nesses termos, conforme Boschetti (2003),0 fato que se destaca é que a discricionariedade de que o governo dispõe para executar as emendas se traduz claramente em caráter partidário para o favorecimento das suas coalizões, uma vez que as emendas pagas são, em sua maioria, dos partidos da base de apoio ao governo em detrimento daqueles opositores. Esse comportamento afronta vários preceitos constitucionais, tais como a igualdade, a impessoalidade, moralidade e o pluralismo político. Assim, a filiação partidária é a variável dicotômica para atender as emendas de deputados e senadores, isto é, as emendas de parlamentares da bancada governista e da base de apoio "têm maiores chances de serem executadas em detrimento aos demais parlamentares" (FIGUEIREDO; LIMONGI, 2002, p. 763).

Outro fato que chama atenção na junção dos períodos são as liquidações em favor do Partido Comunista do Brasil - PCdoB - (6ํㅡㄴ colocado no período 1 e $5^{\circ}$ no período 2$)$, e do próprio Partido Republicano Brasileiro- PRB- (líder do período 2), ambos, embora com representatividade baixa no Congresso, foram protagonistas na gestão do ME. A primeira agremiação comandou a pasta desde sua criação em 2003 até 2015, ano em que o PRB a assumiu. Tal cenário contribuiu consideravelmente na dinâmica das emendas apresentadas e posteriormente liquidadas (TEIXEIRA, 2016).

Sobre este aspecto, Bezerra (1999) alerta que se o interesse dos parlamentares é garantir que os recursos sejam destinados conforme seus objetivos, notadamente os eleitoreiros, o interesse dos ministros consiste em assegurar que tais valores sejam aprovados sob a forma de dotações globais, quer dizer, montantes não vinculados à realização de um programa em uma dada região ou município e cuja aplicação é definida geralmente pelos próprios ministros conforme suas preferências.

Sabendo dessa dinâmica, nos termos de Bezerra (1999), e considerando o vínculo partidário, as lideranças políticas e os parlamentares procuram, já durante a elaboração do orçamento, aprovar recursos para os ministérios que estão sob a gestão de membros de seu partido ou pelo menos da base aliada. Além disso, as relações de amizade, os compromissos políticos, a possibilidade de recorrer a mediações e o prestígio do parlamentar junto ao ministro são, entre outros, alguns dos fatores que intervêm na priorização do atendimento dos pleitos dos parlamentares. 
Desta forma, a relação entre o Poder Executivo (presidência e ministros) e o Poder Legislativo (senadores e deputados) é uma via de mão dupla, em que o Executivo busca liquidar as emendas para agradar o Legislativo para conseguir seu apoio, enquanto este busca ter emendas liquidadas, sobretudo em seu reduto eleitoral, para ter um maior quantitativo de votos (BEZERRA, 1999; TEIXEIRA, 2016).

\section{CONSIDERAÇÕES FINAIS}

Avaliando todo o panorama, tais dados revelam a significativa representatividade das emendas na execução orçamentária do ME, notadamente nos anos vinculados ao PPA $2008 / 2011$, os quais atingiram média de $72 \%$ de todo orçamento ministerial. Ao mesmo tempo é possível identificar a prática clientelista no uso de recursos públicos pelos parlamentares, sobretudo no que se relaciona aos votos em plenário conforme interesses do governo e das emendas direcionadas para beneficiar suas bases eleitorais, fortalecendo seus partidos e, assim, mantendo o poder à custa do erário.

Essa prática, além de direcionar recursos do governo para projetos locais, garantidos exclusiva ou principalmente para trazer dinheiro para um representante do distrito, é utilizada para reforçar relações entre pessoas que se encontram em termos econômicos e de poder em situação de desigualdade. Nesses casos, reiteramos que as práticas clientelistas são consideradas, sobretudo, um meio do Estado e dos políticos atenderem às demandas específicas das populações mais pobres e integrá-las ao sistema político, cooptando novos grupos sociais.

Quando se observam os dados, no período do PPA 2008/2011, a liquidação de emendas estava diretamente vinculada a uma boa relação entre os dois poderes, bem como à coalizão. Já no PPA 2012/2015 nota-se uma ruptura com a harmonia da coalizão. Ao liquidar um quantitativo ínfimo das emendas, o Executivo minimizou um dos principais instrumentos eleitorais de deputados e senadores, ocasionando, dentre outros fatores, uma crise política sem precedentes.

Assim, recursos que poderiam compor a dotação global para o setor e previstos nos instrumentos norteadores das políticas esportivas, quando marcados sob a forma das emendas, adotam uma lógica de favorecimento da "pequena política", reproduzindo práticas clientelistas tão presentes em nossa tradição política, atendendo diretamente aos interesses do capital.

Para superar tais mazelas e minimizar tais aspectos, no caso esportivo deve-se retomar as estratégias definidas a partir da I e II Conferência Nacional do Esporte, ou seja, estabelecer um Sistema Nacional do Esporte que tenha como princípio assegurar o esporte como direito de todos, com investimentos em infraestrutura (desvinculado do atendimento de clientelas), na formação inicial e continuada de profissionais, no estabelecimento de um sistema nacional descentralizado de financiamento, associado com o conhecimento científico produzido nas universidades, bem como estratégias claras baseadas em um plano amplo e exequível para o setor. 


\section{REFERÊNCIAS}

ALMEIDA, Bárbara Schausteck. 0 financiamento do esporte olímpico e as suas relações com a política no Brasil. 2010.119f. Dissertação (Mestrado em Educação Física) Departamento de Educação Física, Universidade Federal do Paraná; Curitiba, 2010.

ATHAYDE, Pedro Fernando; SALVADOR, Evilásio; MASCARENHAS, Fernando. Primeiras aproximações de uma análise do financiamento da política nacional de esporte e lazer no governo Lula. In: MATIAS, Wagner Barbosa.; ATHAYDE, Pedro Fernando; MASCARENHAS, Fernando. Políticas de esporte nos anos Lula e Dilma. Brasília: Thesaurus, 2015. p. 117-139.

BEZERRA, Marcos Otávio. Em nome das "bases": política, favor e dependência pessoal. Rio de Janeiro: Relume Dumará, 1999.

BOSCHETTI, Ivanete. Implicações da Reforma da Previdência Social na Seguridade Social Brasileira. Revista Psicologia e Sociedade, v. 15, n. 1, p. 57-96, 2003.

BOSCHETTI, Ivanete. Avaliação de políticas, programas e projetos sociais. In: Serviço Social: Direitos Sociais e Competências Profissionais. Brasília: CFESS, ABEPSS, 2009.p. 1-20.

BOUDENS, Emile Paulo Johannes. 0 financiamento do esporte no primeiro mandato de Lula (2003-2006). Rio de Janeiro: T +8; Usina de Letras, 2007.

CASTELAN, Lia Polegato. As conferências nacionais do esporte na configuração da política esportiva e de lazer no governo Lula (2003-2010). Campinas, 2011. 188f. Dissertação (Mestrado em Educação Física) - Faculdade de Educação Física, Universidade Estadual de Campinas, Unicamp, 2011.

CASTRO, Suelen Barboza Eiras. Políticas Públicas para o Esporte e Lazer e o Ciclo Orçamentário Brasileiro (2004-2011): Prioridade e distribuição de recursos durante os processos de elaboração e execução orçamentária. Curitiba, 2017. 382f. Tese (Doutorado em Educação Física) - Setor de Ciências Biológicas, Universidade Federal do Paraná, 2016.

COUTINHO, Carlos Nelson. A hegemonia da pequena política. In: OLIVEIRA, F.; BRAGA, R; RIZEC, C. (Orgs.). Hegemonia às avessas: economia, política e cultura na era da servidão financeira. São Paulo: Boitempo, 2010. p. 29-43.

FIGUEIREDO, Argelina; LIMONGI Fernando. Incentivos Eleitorais, Partidos e Política Orçamentária. DADOS: Revista de Ciências Sociais, v. 45, n. 2,p. 303-344,2002.

GONÇALVES, Reinaldo. Desenvolvimento às Avessas: verdade, má-fé e ilusão no atual modelo brasileiro de desenvolvimento. Rio de Janeiro: LTC, 2013.

GRAMSCI, Antônio. Cadernos do cárcere. Tradução de Carlos Nelson Coutinho com a colaboração de Luiz Sergio Henriques e Marco Aurélio Nogueira. Rio de Janeiro: Civilização Brasileira, $2003.5 \mathrm{v}$.

GUIMARÃES, Adriana Aparecida. Políticas Públicas no Âmbito Do Ministério do Esporte e os Planos Plurianuais dos Governos Fernando Henrique Cardoso, Luiz Inácio Lula da Silva e Dilma Rousseff: Com o orçamento quem ganha o quê, quando e como? Ponta Grossa, 2017. 206f. Tese (Doutorado em Cidadania e Políticas Públicas) - Setor de Ciências Sociais, Universidade Estadual de Ponta Grossa, 2017.

MANDEL, Ernest. O capitalismo tardio. 2. ed. São Paulo: Nova Cultural, 1985. 
MASCARENHAS, Fernando. O orçamento do esporte: Aspectos da atuação estatal de FHC à Dilma. Revista Brasileira Educação Física e Esporte, v. 30, n.4, p. 963-980, out./dez. 2016.

MATIAS, Wagner Barbosa et al. A lei de incentivo fiscal e o (não) direito ao esporte no Brasil. Movimento, v.21, n. 1, p. 95-110, jan./mar. de 2015.

MATIAS, Wagner Barbosa. 0 enigma olímpico: o controvertido percurso da agenda e política esportiva no governo Lula. Brasília, 2013. 199f. Dissertação (Mestrado) -Faculdade de Educação Física, UnB, Brasília, 2013.

PEREIRA, Carlos; MUELLER, Bernardo. Comportamento Estratégico em Presidencialismo de Coalizão: As Relações entre Executivo e Legislativo na Elaboração do Orçamento Brasileiro. Revista de Ciências Sociais, v. 45, n. 2, p. 265-301, 2002.

SALVADOR, Evilásio. Fundo público no Brasil: financiamento e destino dos recursos da seguridade social (2000 a 2007). 2008. 395f. Tese (Doutorado em Política Social) Departamento de Serviço Social, Universidade de Brasília. UnB, Brasília, 2008.

TEIXEIRA, Marcelo Resende; MATIAS, Wagner Barbosa; MASCARENHAS, Fernando. 0 financiamento do esporte olímpico no Brasil: uma análise do ciclo de Londres (2009-2012). In: MATIAS, Wagner Barbosa; ATHAYDE, Pedro Fernando; MASCARENHAS, Fernando. Políticas de esporte nos anos Lula e Dilma. Brasília: Thesaurus, 2015. p. 161-186.

TEIXEIRA, Marcelo Resende. Esporte, fundo público e pequena política. 2016.231f. Dissertação (Mestrado em Educação Física) - Faculdade de Educação Física, Universidade de Brasília; Brasília, 2016.

VERONEZ, Luiz Fernando Camargo. Quando o Estado joga a favor do privado: As políticas de esporte após a Constituição Federal de 1988. Campinas, 2005. 370f. Tese (Doutorado em Educação Física) - Faculdade de Educação Física, Universidade Estadual de Campinas: Unicamp, 2005. 